\section{O salto do milênio}

Tradução de Juremir Machado da Silva

\section{Joël de Rosnay \\ Doutor em Ciência}

Diretor de Desenvolvimento e Relações Internacionais da

Cité des Sciences et de l'Industrie/França
EM PLENA CRISE, e às vésperas do século XXI, as sociedades industrializadas enfrentam o novo choque do futuro: a "sociedade informacional". A redução do crescimento econômico, o aumento do desemprego e a contestação do papel tradicional das elites políticas e econômicas traduzem a rapidez da transição entre as sociedades industrial e "informacional". Dessa zona de turbulência, emerge o poder dos grupos face ao poder centralizado, enquanto as redes informáticas e a Internet favorecem a afirmação dos indivíduos face ao anonimato dos "usuários". Mas essas grandes correntes são compreendidas com pertinência e ajudarão a construir com lucidez o mundo de amanhã?

A sociedade industrial caracteriza-se pela centralização dos meios de produção, pela distribuição em massa de objetos padronizados, pela especialização das tarefas e pelo controle hierárquico destas. $\mathrm{O}$ modelo, tomado de empréstimo à geometria ou à mecânica, é a pirâmide ou a correia de transmissão. Os três pilares que sustentam o contrato de trabalho na empresa são a unidade de local, de tempo e de função. Com o advento do tratamento eletrônico das informações, da digitalização dos dados e com o desenvolvimento das redes interativas de comunicação, as referências clássicas despedaçaram-se. Às três unidades (de lugar, de tempo e de função), opõem-se a descentralização das tarefas, a dessincronização das atividades e a desmaterialização das trocas.

A sociedade nascente organiza-se antes em redes do que em pirâmides de poder; em células independentes mais do que em engrenagens hierárquicas; mais num "ecossistema informacional" do que em fileiras industriais lineares. Daí a confusão dos políticos e dos altos funcionários de Estado - alimentados com evoluções quantificáveis, proporcionais e extrapoláveis - diante da irradiação multidimensional ou das acelerações brutais das novas evoluções. A emergência de um fenômeno internacional 
de comunicação, como a Internet, o efeito de surpresa que provocou e a vontade de controle suscitada, ilustram perfeitamente essa perda de referencial.

Outro choque: a emergência das pessoas. Nos nós da rede "informacional" evoluem, doravante, simultaneamente atores diversificados, comunicantes e criadores potenciais: os "neurônios" de um cérebro planetário nascente. Não são mais os "usuários" de antes, passivos utilizadores de serviços pensados por outros, mas os produtores/consumidores de novos instrumentos interativos que multiplicam os poderes e a eficácia de cada um. Esses novos instrumentos são para a sociedade "informacional" o que as máquinas mecânicas eram para a sociedade industrial.

O instrumento básico é o computador pessoal, multimídia e comunicante. Portátil ou fixo, de escritório ou doméstico, "network computer" (NC), terminal reduzido ao mínimo, ou "personal computer" (PC), posto autônomo; a sua influência sobre o crescimento econômico e a sua utilização só fazem intensificar-se. $\mathrm{Na}$ primeira fila dos novos espaços de comunicação aparece a Internet, com um desenvolvimento prodigioso, cujos tentáculos atingirão o próximo século. Internet não é, como se crê freqüentemente, uma rede, mas sim um protocolo comum a todos os computadores e suscetível de utilizar, indiferentemente, inúmeras redes: telefone, sistema internet de empresa, televisão a cabo, satélite, fibra ótica...

O desenvolvimento futuro da Internet passará por fluxos elevados, estimulando a interatividade nos campos da educação, da informação ou do lazer. Essa lógica, levada ao extremo, conduz ao conceito de "empresa unipessoal multinacional": uma pessoa dominando tais instrumentos é doravante capaz de concorrer com empresas já implantadas". O salto do milênio está apenas começando. Compreender o universo imaterial e a emergência da pessoa consiste numa dimensão profunda e significativa do "informacional".

De agora em diante, os políticos terão de gerir a abundância de variedade e de diversidade; logo eles que estavam habituados a um universo regido por estatísticas, probabilidades e sondagens. Um dirigente político de estatura internacional confessou recentemente: “Até o presente, lidávamos com dois tipos de poder cidadão: o dos eleitores e o dos manifestantes. Estávamos acostumados com esse universo. Precisávamos adular os eleitores e temer os manifestantes. Aos primeiros, o voto na urna; aos outros, a rua e a televisão. Para administrar aqueles, promessas eleitorais e ações espetaculares "midiáticas"; para controlar os últimos, a rigidez ou os agentes do CRS. Hoje, com a explosão das redes interativas multimídias, como a Internet, aparece uma nova classe de cidadãos: numerosas pessoas, de diversos horizontes, que desejam exprimir-se. Ainda não sabemos gerir esta nova situação".

Magnífica confissão de impotência do político diante da nova forma de democracia nascida das redes. Defasagem resultante de uma mudança de paradigmas, de um salto cultural. O pensamento cartesiano, analítico, linear, seqüencial e proporcional, partilhado por tantos homens de decisão, políticos e empresários formados em matemática e em direito, pertence ao passado. A cultura da complexidade, parte integrante do novo paradigma, refere-se ao pensamento sistêmico, ao não-linear, ao multidimensional e integra a dinâmica devida aos efeitos de amplificação.

As características do novo espaço econômico, social e cultural imaterial, chamado de "ciberespaço", não se enquadram nas análises dos que vivem e raciocinam conforme o antigo modelo. Eles não as enxergam. O século XXI será da complexidade. Doravante, duas culturas existem portanto entre as autoridades. Assim, uma nova divisão cultural surge, com freqüência mais definida do que as tradicionais separações políticas. E não se trata somente de um fosso entre gerações, mas de uma nova abordagem da complexidade e do meio imaterial. Estamos atualmente num 
ecossistema "informacional" no qual os Estados, as grandes instituições e as empresas cooperam ou concorrem (cooperação-competição). Diferença cultural exemplificada pelo desenvolvimento da nova economia de redes.

Os critérios da sociedade "industrialista" e da economia de mercado não se aplicam mais. Contudo, crescimento, emprego e atividades "sem rentabilidade" poderiam ser complementares, sob a condição de lançar um novo olhar sobre a crise atual. O cerne da economia mercantil garante ao Estado a coleta de impostos e de taxas diversas, assim como das contribuições sociais. Os "motores" do crescimento são a pesquisa, o desenvolvimento industrial e a diversidade dos mercados capaz de assegurar progresso econômico e bem-estar social. A competição e a concorrência estimulam a economia enquanto que o crescimento permite criar os empregos necessários a sua sobrevivência.

Esse esquema manteve pertinente num universo material baseado na produção e na distribuição de objetos manufaturados. Mas já não está mais adaptado à sociedade "informacional", pois se atinge agora, na economia clássica, a lei dos rendimentos decrescentes. Enormes esforços governamentais e investimentos financeiros, industriais e humanos consideráveis são necessários para a obtenção de um fraco aumento dos benefícios, das fatias de mercado ou da competitividade econômica. Tal é a dura lei dos últimos anos: o ganho de produtividade oriundo da automação e da informação acarreta o aparecimento de bolsões irredutíveis de desemprego. No entanto, a esfera das atividades continua em constante desenvolvimento.

A sociedade "informacional" favorece novas trocas, outras formas de transação entre pessoas e amplia os fluxos do tráfego imaterial. Essas novas atividades nem sempre são rentáveis em termos de economia clássica. Traduzem, entretanto, uma forte demanda da sociedade. Como conciliar o cerne da economia mercantil, nascida da industrialização, e a esfera em expansão das atividades atreladas à informática? O século XXI terá de enfrentar este dilema. Deve-se repensar em profundidade a relação entre o tempo e a natureza do trabalho, cujo contrato encerra hoje a lógica do crescimento numa matriz de dimensão única: o tempo contra o salário.

As regras tradicionais de unidade de lugar, de tempo e de função bloqueiam o desenvolvimento da economia "informacional". Mas se é possível trabalhar a distância, pode-se também fazê-lo escolhendo o tempo, realizando tarefas de natureza diferentes. Vê-se assim surgir uma nova categoria sócioeconômica: os "assalariados liberais", consultores, com múltiplos empregadores, conferencistas ou professores, campeões de teleatividades graças aos instrumentos de comunicação e de tratamento da informação. As pesquisas indicam que numerosos assalariados estão abertos a formas complementares de remuneração. Alguns preferem melhorias na qualidade de vida - formação, redução do tempo de trabalho, criação de uma poupança-tempo - a aumentos de salário.

Os freqüentadores das redes on line multimídia já praticam uma nova forma de economia: "a troca de informações". Uma criação original (programa, texto, conselhos, música, gráficos, audiovisual) é colocada gratuitamente à disposição dos usuários. Em contrapartida, os criadores são "remunerados" com informações de maior valor agregado. A matriz convencional ampliase. Os dois termos do contrato de trabalho, tempo e salário, devem ser confrontados com novos elementos: informação, valores, reconhecimento, tempo. Uma das características fundamentais da sociedade "informacional" consiste em estimular novas formas de intercâmbio, de troca de mercadorias.

O desenvolvimento das atividades de benevolência, de assistência humanitária e dos movimentos associativos só tende a acentuar-se. Tais atividades criam "capitaltempo", com o qual se pode fazer frutificar os "interesses", e "capital-informação", que permite, graças ao tempo investido, acelerar 
e tornar mais eficaz o trabalho em equipe em que numerosas unidades funcionam em paralelo. Uma das chaves do desenvolvimento econômico do próximo século abriga-se exatamente neste nicho de transição: visto que parece impossível aumentar o núcleo da economia clássica, por que não tentar fazê-lo do exterior, aspirando-o com esta esfera de atividades inéditas e indiretamente criadora de empregos?

A densidade das trocas e dos contatos na sociedade "informacional" realiza justamente essa ligação. Algo que compreenderam os partidários do desenvolvimento das redes interativas internacionais, chamadas sem razão de "auto-estradas da informação". Estamos longe das infra-estruturas pesadas da sociedade industrial a que se refere essa metáfora rodoviária com seus pedágios e o controle da circulação. Esboça-se antes uma superposição de vasos capilares, de veias e de artérias fortemente ramificados, irrigando todos os ramos da sociedade. As artérias não precederam os vasos. A integração das células em tecidos, em órgãos e em organismos é que tornou necessária a intensificação dos fluxos. Mas a função original era a "regeneração" das células, unidades básicas da vida.

Rumo à fragmentação do tempo e do espaço, o homem e o conteúdo das mensagens que dão sentido à ação estão no centro das redes do futuro. O emprego não resultará de medidas pontuais, incompatíveis umas com as outras, mas de uma mudança das relações entre o tempo, o espaço e o trabalho, ou seja, da introdução do novo paradigma numa sociedade interativa e de responsabilidade. A visão política originária da industrialização continua prisioneira de uma lógica herdada do século XIX: gestão da escassez, concentração na produção e na distribuição, especialização das tarefas, controle e programação das atividades.

Doravante, trata-se da gestão da abundância (especialmente da informação) e da obsolescência, da importância da transação; pilotagem e catálise são as palavras determinantes da sociedade "informacional".
Deve-se favorecer tudo o que aumenta a densidade das relações e das transações: dessincronizar as tarefas através do tempo parcial; descentralizar as atividades graças à redução dos custos de comunicação, à democratização e à simplificação do uso de terminais e de computadores pessoais, assim como graças à reorganização dos locais de trabalho (escritórios móveis, empresas virtuais); diversificar as funções, como ajuda aos empreendedores, através da criação de incubadoras de empresa, da concessão das vantagens dadas aos assalariados liberais, da reforma do contrato de trabalho.

É preciso também valorizar a experiência dos mais velhos para que possam transmitir conhecimentos e brilhar durante muito tempo. Tais medidas opõem-se às que operam na atualidade. Deve-se aceitar a realidade: não se trata mais de criar empregos aqui e agora a golpe de decisões governamentais ou de subvenções, mas antes de favorecer os sistemas que inventam empregos. Empregos indiretos em outros lugares, com outros tempos, com outras funções e outros setores econômicos. Essa nova visão choca-se com as práticas das nossas democracias: a circunscrição do eleitorado, a duração do mandato eleitoral ou o pagamento local da taxa profissional.

A sociedade "informacional" desafia as políticas clássicas de apoio ao emprego. Os políticos não devem mais temer a diversidade, mas, ao contrário, favorecê-la. E se não conseguem controlá-la, podem, em contrapartida, "catalisar" a emergência do potencial de cada um. A transição entre as sociedades industrial e "informacional" encontra-se totalmente nesta alternativa: prosseguir o exercício (por vezes solitário) da inteligência eletiva ou favorecer a prática solidária da inteligência coletiva.

A complexidade não se reduz a alguns elementos simples definidos pela análise cartesiana. Constitui-se, ao contrário, pela ação simultânea de pessoas responsáveis, informadas e criativas. O sucesso da grande passagem ao século XXI resultará da responsabilização dos "neurônios" do cérebro 
planetário - os atores personalizados do amanhã .

\section{Notas}

Texto publicado originalmente no Monde diplomatique, de 19 de agosto de 1996, p. 19, sob o título "Ce que va changer la révolution informationnele". Atualizado pelo autor para esta revista. 